\title{
Does increased investment in coronary angiography and revascularisation reduce socioeconomic inequalities in utilisation?
}

\author{
C J Manson-Siddle, M B Robinson
}

\begin{abstract}
Objectives-To investigate whether additional resources for tertiary cardiology services, aimed at increasing coronary angiography and revascularisation rates, can improve socioeconomic equity of utilisation.

Design-Cross sectional ecological study, using the Super Profile classification of enumeration districts and ischaemic heart disease (IHD) standardised mortality ratios (SMR) as a proxy for need. The degree of equity before the provision of extra resources was determined using data for April 1992 to March 1994, and the corresponding picture after, using data for April 1994 to March 1996.
\end{abstract}

Setting-South Humberside (United Health - Grimsby and Scunthorpe Health Authority, a district of the former Yorkshire Region, before the April 1996 boundary changes).

Subjects-Patients with a primary diagnosis of IHD aged $\geqslant 25$ years who underwent investigation by angiography, or treatment by coronary artery bypass grafting or percutaneous transluminal coronary angioplasty, as a primary procedure.

Main results-In 1992/4, before concerted intervention, both investigation and revascularisation rates, although increasing, were low in Grimsby and Scunthorpe district compared with most other districts in the Yorkshire Region. Also, there was a decreasing trend across Super Profile Lifestyle groups from the Affluent Achievers to the Have-Nots despite a twofold increase in SMRs indicating the greater need of the more deprived. After appointing a consultant general physician with an interest in cardiology in the Scunthorpe district general hospital in 1994; arranging for both the Grimsby physician and the Scunthorpe physician to undertake angiography at a neighbouring district tertiary cardiology centre in 1995; together with significant additional health authority investment in cardiac procedures in 1995/6, district rates increased considerably, (a $41 \%$ increase in investigation and a $47 \%$ increase in revascularisation rates). Also, after additional resource input began, the trend for angiographies across socioeconomic groups clearly be- came more equitable, although increased equity for revascularisations is less apparent.

Conclusion-Early indications are that additional resources for tertiary cardiology may have reduced socioeconomic inequities in angiography, without being specifically targeted at the needier, more deprived groups. Improvement in socioeconomic equity of utilisation of revascularisation is not yet clear, although data for April 1996 to March 1998 (after a lengthier intervention period) may confirm improved equity. Should this not be so, it might be necessary to specifically target resources to the deprived to increase equity in revascularisation.

(F Epidemiol Community Health 1999;53:572-577)

The socioeconomically disadvantaged have been shown both nationally and locally to experience a greater burden of coronary heart disease mortality than the privileged. ${ }^{12}$ Similarly, they have also been shown to experience more ill health. ${ }^{3}$ Investigation by coronary angiography followed, where appropriate, by revascularisation using coronary artery bypass grafting (CABG) or percutaneous transluminal coronary angioplasty (PTCA), has been shown to be effective both in prolonging the life of those with extensive coronary disease at moderate to high risk, and in improving the quality of life..$^{4-9}$ Given the founding principle of an equitable NHS, and that clinical effectiveness is evident, it would be expected that the socioeconomically disadvantaged would therefore also experience more coronary angiographies and CABGs/PTCAs - that is, equal utilisation for equal need.

Previously, the medical literature examining the relation between socioeconomic status and coronary angiography/revascularisation rates, had shown contradictory results, possibly attributable in part to the different methodologies used. ${ }^{10-14}$ Using Super Profile analysis, we confirmed socioeconomic inequity in both coronary angiography and revascularisation within the former Yorkshire Region in the period 1992-1994..$^{15}$

The Super Profile ${ }^{16}$ methodology uses multivariate techniques to combine 120 census variables that indicate deprivation - that is, a multidimensional view to more accurately reflect the multidimensional nature of socioeconomic circumstance. It uses enumeration districts (EDs), the smallest geographical area for which the data are available, to limit the scope for 
Table 1 Super Profile Lifestyle Groups

\begin{tabular}{ll}
\hline I Affluent Achievers & $\begin{array}{l}\text { Mainly middle aged professional couples with children at } \\
\text { university, living in their own large detached homes. } \\
\text { Mainly young/middle aged adults living in detached homes, } \\
\text { often working there, for example, farmers, and often owning a } \\
\text { second home. }\end{array}$ \\
Mainly older middle aged professionals or managers, semi or \\
detached home owners whose children have left home. \\
Many older couples with children living in semi-detached houses \\
IV Settled Suburbans & $\begin{array}{l}\text { and having white collar occupations, with part time working } \\
\text { housewives. }\end{array}$ \\
V Nest Builders & $\begin{array}{l}\text { Young, often double income, white collar or skilled manual } \\
\text { families living in mortgaged semi-detached or terrace homes, } \\
\text { including military families. }\end{array}$ \\
VI Producers & $\begin{array}{l}\text { Usually older, blue collar, owner occupiers of semis or living in } \\
\text { council houses. }\end{array}$ \\
VII Senior Citizens & $\begin{array}{l}\text { Older, retired couples or single old ladies living alone, or young } \\
\text { single transients living in seaside towns, both groups buying } \\
\text { terrace houses or flats. }\end{array}$ \\
VIII Urban Venturers & $\begin{array}{l}\text { High proportion of ethnic minorities, also members of armed } \\
\text { forces, high income young professionals renting in London, } \\
\text { many non-car owners. }\end{array}$ \\
IX Hard-Pressed Families & $\begin{array}{l}\text { High numbers of young people and single parents living in } \\
\text { council terraces, often unemployed and non-car owners } \\
\text { Many single parent families and few married couples, living in } \\
\text { crowded, rented or council accommodation, often unemployed } \\
\text { and non-car owners }\end{array}$ \\
X Have-Nots &
\end{tabular}

ecological fallacy. These highly correlated variables are transformed using principal component analysis to fewer less correlated variables, while maintaining as much of the original data as possible. Cluster analysis then groups EDs with similar characteristics at three levels. The most aggregated level is used for this analysis with the 10 Lifestyle groups sequenced using the scores of the first principal component to form an index of affluence (table 1). The usefulness of the methodology has previously been demonstrated in health services research. ${ }^{17-20}$

Our study ${ }^{15}$ showed a twofold to threefold difference in overall rates between districts, and a similar difference between district rates for different Lifestyle groups (table 2). In general, districts with high procedure rates (for example, Leeds, a geographically small but densely populated district with two NHS tertiary cardiology centres and private provision) had the most equitable utilisation across Super Profile groups. In districts where procedure rates were low despite high standard mortality ratios (SMRs) (including United Health Grimsby and Scunthorpe Health Authority district, with no tertiary centre or private

Table 2 SMRs and average annual (1992-4) age-sex standardised investigation and revascularisation rates/million with $95 \%$ confidence intervals, aged 25 years and over

\begin{tabular}{|c|c|c|c|c|}
\hline Geographical area & $\begin{array}{l}\text { CHD } \\
\text { SMR }\end{array}$ & District rates & $\begin{array}{l}\text { I Affluent Achievers } \\
\text { rates }\end{array}$ & $X$ Have-Nots rates \\
\hline \multicolumn{5}{|l|}{ Angiography rates } \\
\hline $\begin{array}{l}\text { Leeds } \\
\end{array}$ & 100 & $2643(2532,2754)$ & $1755(1470,2040)$ & $3323(2929,3717)$ \\
\hline United Health & 119 & $1272(1166,1377)$ & $1489(1082,1985)$ & $1205(851,1558)$ \\
\hline West Yorkshire & 121 & $1296(1208,1384)$ & $1137(849,1424)$ & $1533(1146,1920)$ \\
\hline Bradford & 113 & $960(874,1046)$ & $716(462,970)$ & $1168(855,1481)$ \\
\hline Wakefield & 121 & $1902(1798,2007)$ & $1302(818,1786)$ & $2063(1521,2605)$ \\
\hline North Yorkshire & 103 & $1043(975,1110)$ & $885(705,1064)$ & $1677(1111,2243)$ \\
\hline East Riding & 106 & $1613(1513,1713)$ & $1328(1018,1639)$ & $1862(1544,2180)$ \\
\hline \multicolumn{5}{|l|}{$C A B G$ rates } \\
\hline Leeds & 100 & $1587(1501,1673)$ & $1001(785,1217)$ & $1869(1577,2161)$ \\
\hline United Health & 119 & $690(612,768)$ & $1006(671,1340)$ & $659(399,920)$ \\
\hline West Yorkshire & 121 & $796(727,866)$ & $1023(748,1298)$ & $641(386,895)$ \\
\hline Bradford & 113 & $804(725,833)$ & $567(343,792)$ & $1002(711,1294)$ \\
\hline Wakefield & 121 & $1056(952,1160)$ & $721(366,1077)$ & $1252(821,1684)$ \\
\hline North Yorkshire & 103 & $662(608,715)$ & $642(492,793)$ & $784(394,1175)$ \\
\hline East Riding & 106 & $885(811,959)$ & $759(523,995)$ & $854(639,1069)$ \\
\hline
\end{tabular}

$\mathrm{CHD}=$ coronary heart disease. providers), utilisation was inequitable across socioeconomic groups.

Although the ideal rate for revascularisation is unknown, the British Cardiac Society (1994) has recommended 1000 CABG/PTCA procedures per million total population. ${ }^{21}$ Does the provision of extra resources to increase angiography and revascularisation rates in districts currently well below this recommended level result in increasing equity of utilisation - that is, does the uptake in such circumstances improve most in the poorest groups? Or, does providing extra resources without actively targeting the needy deprived groups simply maintain the status quo, reinforcing the Inverse Care Law? ${ }^{22}$

\section{Method}

The aim of this research was to examine the impact on socioeconomic differences in coronary investigation and revascularisation utilisation rates, of increasing resources for cardiology, in one district-United Health (Grimsby \& Scunthorpe Health Authority):

(1) the appointment of a general physician with an interest in cardiology in 1994 in Scunthorpe, such that there was one cardiologist at each of the two district general hospitals (Grimsby and Scunthorpe).

(2) arrangements introduced in 1995 for both these physicians to undertake angiography procedures on district residents in neighbouring East Riding district, at Castle Hill Hospital's new catheter laboratory (three sessions per week were purchased, with the two physicians alternating and covering to provide an all year round service, at a throughput of 4-6 United Health patients per session).

(3) extra untargeted expenditure on cardiac procedures (angiography, PTCA, CABG) starting in 1995-an additional £1/2 million, a $40 \%$ increase on the $1993 / 4 £ 1.4$ million expenditure.

The population of United Health district was approximately 360000 in 1992/4. Before increased resources, apart from a very few procedures undertaken in specialist centres elsewhere, the majority of angiograms and PTCAs were undertaken at Hull Royal Infirmary (Royal Hull Hospitals), and CABGs at Castle Hill Hospital (East Yorkshire Hospitals) in neighbouring East Riding Health Authority district, north of the River Humber. There was one catheter laboratory on the north bank, at Hull Royal Infirmary, running an extended service to undertake 1600 angiographies per year, the recommended being 1200 per year. There was a consultant general practitioner with an interest in cardiology in post at the Grimsby district general hospital, but not at the Scunthorpe hospital. People with heart disease were referred to the north bank cardiologists either directly by their general practitioner or by general physicians at the two local hospitals. Grimsby hospital had the facilities to offer complete non-interventional assessment, but the service at Scunthorpe was more limited at this time. The consultant physician in Grimsby had limited informal access to the catheter 


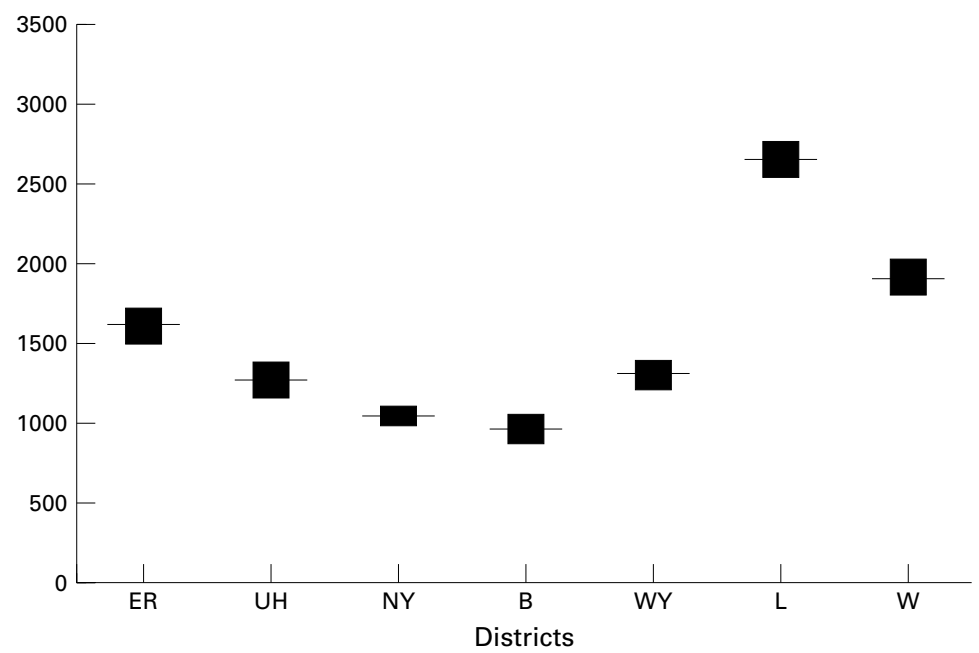

Figure 1 Average annual age/sex standardised angiography rates per milion for 1992/4 with 95\% confidence intervals, all districts former Yorkshire Region. ER= East Riding, UH $=$ United Health, $N Y=$ North Yorkshire, $B=$ Bradford, $W Y=$ West Yorkshire, $L=$ Leeds, $W=$ Wakefield .

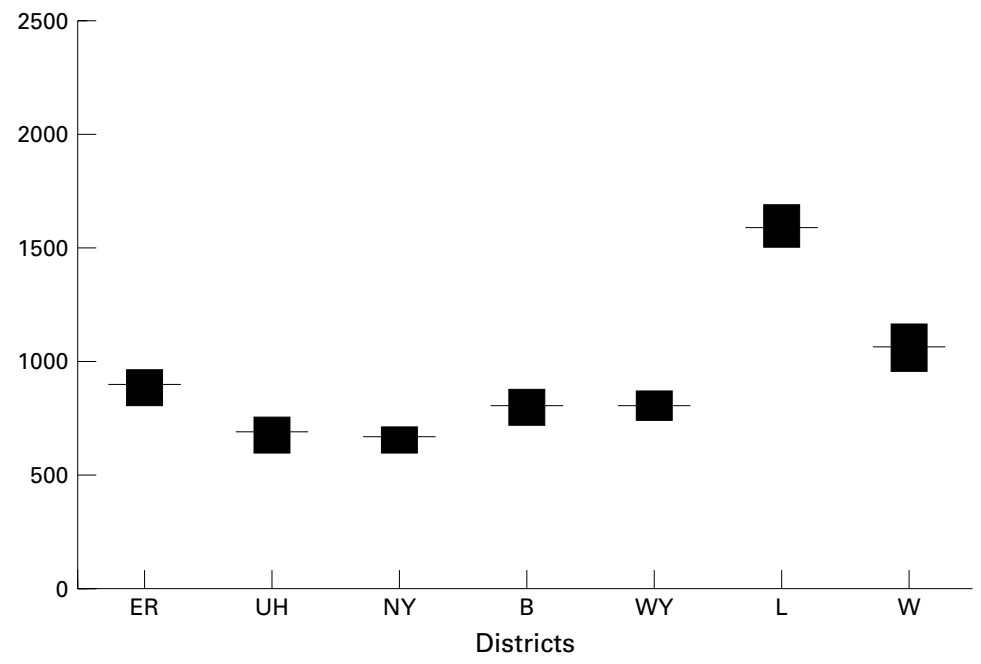

Figure 2 Average annual age/sex standardised CABG/PTCA rates per million for 1992/4 with 95\% confidence intervals, all districts former Yorkshire Region. Abbreviations as in figure 1.

laboratory at Hull Royal Infirmary to undertake angiography under supervision, for a single session ( $1 / 2$ day) each week at a rate of 2-3 each session, but not necessarily on United Health patients. There were no private providers of tertiary cardiology services in the United Health area, the nearest being at Leeds.

The method, together with a discussion of the use and limitations of Super Profile Lifestyle groupings (table 1) is described in detail elsewhere. ${ }^{15}$ In summary, 1991 census population for the former Yorkshire Region and its seven constituent districts were electronically assigned to a Lifestyle group, by gender and five year age band, according to ED characteristics. These data provided the population denominator. Using regionally collated hospital activity data, ${ }^{23}$ patients aged $\geqslant 25$ years with a primary diagnosis of ischaemic heart disease who underwent coronary angiography, CABG or PTCA as a primary procedure were also assigned to a Lifestyle group, using their postcodes. Average annual age standardised utilisation rates per million population were calculated for the region and for each district by Lifestyle group using 1992-4 activity data, standardised to the European Standard Population. ${ }^{24}$ Utilisation rates were also calculated using 1994-6 activity data for residents of the United Health district. It should be noted that as rates per million quoted are for those aged $\geqslant 25$ years, they are around $30 \%$ higher than if a total population rate were calculated. Ischaemic heart disease standardised mortality ratios for Lifestyle groups were used as a proxy for need. ${ }^{25}$

\section{Results}

United Health investigation rates (19921994), before increasing resource input, were the third lowest of the seven health authorities in the Yorkshire Region despite the district's high SMR (119 in 1993) (fig 1). Revascularisation rates were the second lowest, there being an almost threefold difference across districts (fig 2). Within the district, both investigation and revascularisation rates were inequitable, there being a decreasing trend across Super Profile Lifestyle groups from the Affluent Achievers to the Have-Nots despite a twofold increase in SMRs indicating the greater need of the more deprived (figs 3 and 4). The ratio of the angiography rate for the Affluent Achievers to that for the Have-Nots was 1.2:1 (that is, the angiography rate for the most deprived group was $19 \%$ less than that for the most affluent group, a difference of 284 per million procedures, table 3). The corresponding ratio for revascularisation rates was $1.53: 1$ (that is, $34 \%$ less procedures for the Have-Nots than the Affluent Achievers, or 347 per million less, table 3). Had private hospital data been available, and an additional $10-20 \%$ procedures included in the analysis, these ratios would have been greater. ${ }^{25}$

After a concerted effort to increase resources for tertiary cardiology in Grimsby and Scunthorpe district, considerably higher overall procedure rates for $1994 / 6$ were achieved (a $41 \%$ increase in investigation and a $47 \%$

Table 3 United Health investigation and revascularisation average annual rates/million population aged 25 years and over with a primary diagnosis of ischaemic heart disease

\begin{tabular}{|c|c|c|c|c|c|c|}
\hline \multirow{2}{*}{$\frac{\text { Time Period }}{1992-4}$} & \multicolumn{3}{|c|}{ Angiography average annual rate per million (with $95 \%$ confidence intervals) } & \multicolumn{3}{|c|}{$\begin{array}{l}\text { CABG/PTCA average annual rate per million (with } 95 \% \text { confidence } \\
\text { intervals) }\end{array}$} \\
\hline & $1272(1166,1377)$ & & & $690(612,768)$ & & \\
\hline $1994-6$ & $1796(1690,1902)$ & & & $1012(935,1090)$ & & \\
\hline \multirow[t]{2}{*}{ Change } & $41 \%$ increase & & & $47 \%$ increase & & \\
\hline & Affluent Achievers & Have-Nots & Difference & Affluent Achievers & Have-Nots & Difference \\
\hline $1992-4$ & $1489(1082,1985)$ & $1205(851,1558)$ & $-284(\mathrm{HN} 19 \%<\mathrm{AA})$ & $1006(671,1340)$ & $659(399,920)$ & $-347(\mathrm{HN} 34 \%<\mathrm{AA})$ \\
\hline $1994-6$ & $1362(956,1769)$ & $2188(1835,2541)$ & $+826(\mathrm{HN} 61 \%>\mathrm{AA})$ & $653(319,988)$ & $918(657,1178)$ & $+265(\mathrm{HN} 41 \%>\mathrm{AA})$ \\
\hline
\end{tabular}




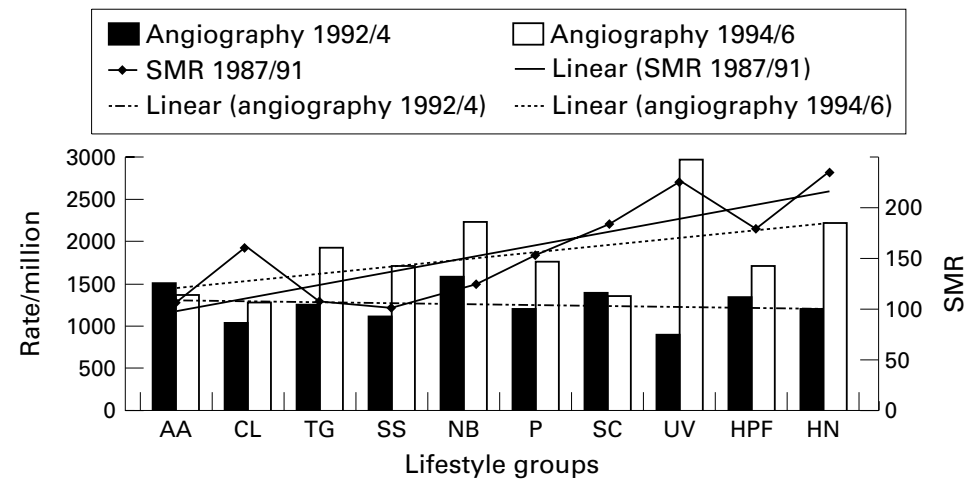

Figure 3 Age/sex standardised angiography rates for 1992/4 and 1994/6, SMRs for $1987 / 91$.

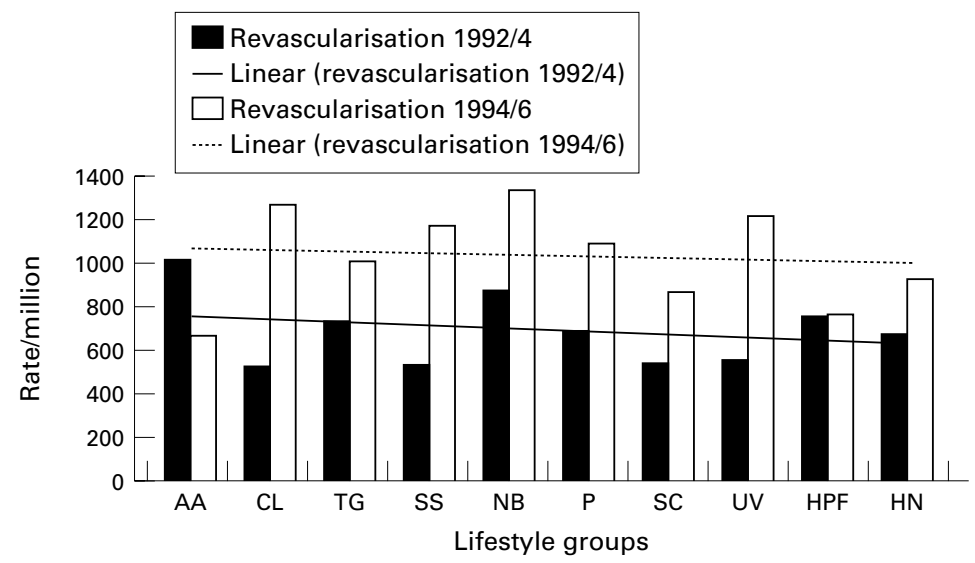

Figure 4 Age/sex standardised CABG/PTCA rates for 1992/4 and 1994/6. Regression analysis is used for linear trends.

increase in revascularisation rates), table 3 . Early indications reveal the trend for angiographies across socioeconomic groups also became more equitable (fig 3). The ratio of angiography rates in the most affluent group (Affluent Achievers) to that in the most deprived group (Have-Nots) decreased by $48 \%$ to $0.62: 1$. The most deprived now received $61 \%$ more investigations than the most affluent-that is, a rate difference of +826 angiographies per million (table 3 ). To test this perceived improvement statistically, the ratios of angiography rate to SMR for Lifestyle groups I-IX, Country Life to Have-Nots, were subtracted from the ratio for Affluent Achievers in the period 1992/4 and repeated for $1994 / 6$. On the premise that for equity on the basis of need as determined by SMR all ratios should be the same as for the most affluent group, mean differences before and after were compared using Student's paired $t$ test. The ratio of angiography rate to SMR by deprivation was significantly closer to the most affluent group (Affluent Achievers I) for all other Lifestyle groups (II to X) in 1994/6 than in $1992 / 4$, $(t=-5.71, \mathrm{p}<0.001$, mean difference 1992/4= -7.46 , mean difference $1994 / 6=-1.2$ ) confirming improved equity.

The ratio of revascularisation rates in the Affluent Achievers to that in the Have-Nots also decreased, this time by $54 \%$ to $0.71: 1$, with the most deprived now receiving $41 \%$ more (265 per million more) procedures than the most affluent (table 3). However, the
KEY POINTS

- Districts with high overall intervention rates (angiography and revascularisation) have equitable provision across socioeconomic groups.

- Within districts with low overall rates, deprived Super Profile groups with high SMRs have lower intervention rates.

- Increasing resources for tertiary cardiology in one district so that overall intervention rates attained recommended levels increased equity across socioeconomic groups despite no specific targeting.

- Reducing inequalities in coronary heart disease is an Our Healthier Nation priority. Increasing district rates to recommended levels may help in part to achieve this target.

considerable variation in rates across the Lifestyle groups resulted in little improvement in the linear trend for revascularisations (fig 4). The ratio of revascularisation rate to SMR by deprivation was, however, also closer to the most affluent group in the latter period than in the former $(t=-10.12, \mathrm{p}<0.001$, mean difference $1992 / 4=-6.56$, mean difference $1994 / 6$ $=0.92$ ), again indicating improved socioeconomic equity.

\section{Discussion}

It is now openly accepted that socioeconomic inequalities in health can be reduced $b^{26}$ :

(1) improving social and economic circumstances of society's poorer groups,

(2) improving environmental conditions, and (3) encouraging healthier behaviours.

Despite having a government openly committed to reducing inequalities, tackling the first two will be a long and difficult process, and there is little evidence of the effectiveness of health promotion programmes designed to tackle the third. ${ }^{27}$

Access to high quality services is also recognised as an important determinant of health status. ${ }^{28}$ It has been suggested that policies designed to equalise access to acute health services, while doing little to tackle the underlying causes of inequalities in health status, might be much more cost effective in tackling the consequences of deprivation. ${ }^{29}$ It would be expected, therefore, that ensuring better access to angiography and revascularisation for people with coronary heart disease in more deprived areas, would help to reduce inequalities in ill health and in mortality ${ }^{30}$ in the interim period.

Targeting deprived groups for investigation and treatment for heart disease is more difficult than targeting for health education, as service related factors (clinical judgement, attitudes to patients, appropriateness) as well as patient related factors (attitudes, expectations, illness behaviours) are important. Such a process could be facilitated by "flagging" the health records of patients from deprived areas.

Increasing overall resources in an untargeted manner is much simpler. Previous studies examining impact on socioeconomic inequality 
of uptake have looked mainly at prevention interventions. Reading $e t a l^{30}$ found that despite substantial increases in immunisation uptake, inequalities persisted or widened, whereas Smith et $a l^{11}$ found that improvements in vision screening coverage selectively benefited children from poorer areas.

Early indications from this study have shown that increasing overall resource input to tertiary cardiology may narrow inequalities in angiography utilisation rates between the socioeconomically deprived (Have-Nots) and the privileged (Affluent Achievers). This may mean that the needs of the articulate and more demanding affluent were already being met, and additional resources began to meet more of the needs of the less empowered, less advocated deprived. This would suggest there is a minimum (threshold) angiography rate required below which inequity is probable.

Angiography is the gateway to revascularisation, ${ }^{32}$ but there is less clear evidence of a corresponding effect on revascularisation. Statistical significance testing suggests improved equity, but regression analysis (linear trend) shows little improvement. The latter may, however, be skewed by outlier points, for example, Country Life group. It also may be that insufficient time has elapsed since the interventions were introduced in 1994 and 1995, and that when 1996/8 HES data become available greater equity will be clearly shown here as well. Should this not be seen then either the revascularisation rate is still too low to meet overall need, or equity can only be achieved by specifically targeting those in lower socioeconomic groups. This may be difficult to determine without private hospital data to assess any concurrent changes in privately purchased procedures. Other potential explanations are that contraindications to revascularisation, for example, obesity, smoking, comorbidities, possibly more prevalent in lower socioeconomic groups may influence clinical appropriateness for revascularisation, or that angiography revealed more noncardiac disease in lower socioeconomic groups. This latter hypothesis is unlikely as investigations are more likely to be undertaken to allay the fears of the middle class "worried well". A detailed case-not study would be required to ascertain this.

Although this research suggests that an untargeted increase in resources for tertiary cardiology services can narrow socioeconomic inequalities in service utilisation, methodological limitations have to be considered. These have been discussed in depth elsewhere. ${ }^{15}$ It is considered that scope for the ecological fallacy to operate is limited. Geographical proximity has also been shown elsewhere in part to explain differences in revascularisation rates. ${ }^{25}$ This may be responsible for the very high rates shown in Leeds, a district with two providers of tertiary cardiology services (at the time of study) despite a relatively small geographical area. However, Grimsby and Scunthorpe district was chosen for the examination of the impact of increased resource because it has no tertiary centre. Hence, differences shown are over and above those resulting from geographical proximity.

Finally, reducing inequalities in coronary heart disease is an "Our Healthier Nation" 26 priority. While it is not possible to prove our interventions are solely responsible for the increased equity shown, increasing district rates to recommended levels may begin to reduce the gap between the privileged and the deprived, particularly if specifically targeted.

We thank John Reed of the Information Department of the former Yorkshire Regional Health Authority for hospital episode data, and Mike Ditchfield, Assistant Director of Commissioning at United Health (now South Humber Health Authority) for information about changes in tertiary cardiology service provision. We also thank Professor Bob Haward, former Director of Public Health for YRHA for permission to use SMRs from the 1994 annual report.

Funding: South Humber Health Authority.

Conflicts of interest: none.

1 Curtis S, Eames M, Ben-Shlomo Y, et al. Geographical differences in CHD mortality in England: implications for local health planning. Health Education fournal 1993;52:72-8.

2 Stringfellow C. Ischaemic heart disease. Poor man's disease in rich man's society. Interim Report No. 1. Mortality analysis. Brigg: United Health, 1993.

3 Stringfellow C. Ischaemic heart disease. Poor man's disease in rich man's society. Interim Report No. 2. Hospital admission data. Brigg: United Health, 1994

4 Yusef S, Zucker D, Peduzzi P, et al. Effect of coronary artery bypass graft surgery on survival: overview of 10 -year results from randomised trials by the Coronary Artery Bypass from randomised trials by the Coronary Artery Bypass Graft Sur

5 Varnauskas E, European Coronary Surgery Study Group. Twelve-year follow-up of survival in the randomised European Coronary Surgery Study. N Engl f Med 1988;319. pean Cort.

6 Gunnell D, Smith L. The invasive management of ischaemic heart disease. Bristol: Health Care Evaluation Unit, University of Bristol, 1994

7 Hubner P J B for British Cardiac Intervention Society. Cardiac interventional procedure in the United Kingdom during 1990. Br Heart f 1992;68:434-6.

8 Meier B, Gruentzig AR, Siegenthaler WE, et al. Long-term exercise performance after percutaneous transluminal coronary angioplasty and coronary bypass grafting. Circulation 1983;68:796-802

9 Pringle SD, Boon NA. Immediate coronary angioplasty for acute myocardial infarction. BMF 1993;306:1489-90.

10 Ben-Shlomo Y, Chaturvedi N. Assessing equity in access to health care provision in the UK: does where you live affect your chance of getting a coronary artery bypass graft? $\mathcal{F}$ Epidemiol Community Health 1995;49:200-4.

11 Kee F, Gaffney B, Currie S, et al. Access to coronary catheterisation: fair shares for all? BMF 1993;307:1306-7.

12 Findlay IN, Dargie HK, Dyke T. Coronary angiography in Glasgow: relation to coronary artery disease and social class. Br Heart $\mathcal{F} 1991 ; 66: 70$.

13 Black N, Langham S, Pettigrew M. Coronary revascularisation: why do rates vary geographically in the UK? I Epidemiol Community Health 1995;49:408-12.

14 Payne N, Saul C. Variations in use of cardiology services in a health authority: comparison of coronary artery revascularisation rates with prevalence of angina and coronary mortality. BMF 1997;314:257-61.

15 Manson-Siddle CJ, Robinson MB. Super Profile analysis of socioeconomic variations in coronary investigation and revascularisation rates. I Epidemiol Community Health 1998;52:507-12.

16 CDMS Super Profiles 91 Crosby, Liverpool: CDMS Marketing Services, 1994.

17 Brown PJB, Hirschfield A, Batey PWJ. Applications of geodemographic methods in the analysis of health condition data. The fournal of the RSAI 1991;70:329-44

18 Reading RF, Openshaw S, Jarvis SN. Measuring child health inequalities using aggregations of Enumeration Districts. $\mathcal{F}$ Public Health Med 1990:12:160-7.

19 Yorkshire Health. Public Health Report 1994 (Statistical Review). A census based view of the population and its health. Harrogate: Yorkshire Health, 1994

20 Reading R, Openshaw S, Jarvis SN. Are multidimensional social classifications of areas useful in UK Health service research? f Epidemiol Community Health 1994;48:192-200.

21 British Cardiac Society. Council statement on the demand and need for cardiac services and the development of a waiting list strategy for cardiac disease. London: British Cardiac society, strategy for $1994: 2$.

22 Hart JT. The inverse care law. Lancet 1971;i:405-12.

3 NHS Executive Northern and Yorkshire. Hospital Activity Data on CD-ROM, 1971-1996, County Durham. 
24 Department of Health. The health of the nation. London: HMSO, 1992.

25 Clinical Standards Advisory Group. Coronary artery bypass grafting and coronary angioplasty. London: HMSO, 1993.

26 Department of Health. Our healthier nation. London: The Stationery Office, Green Paper, 1998

27 NHS Centre for Reviews and Dissemination. A review of the research on the effectiveness of health service interventions reduce variations in health: CRD Report 3 . York: The University of York, 1995.

28 Foster P. Inequalities in health: what health systems can and cannot do. F Health Serv Res Policy 1996;1:179-82.
29 Arblaster L, Lambert M, Entwistle V, et al. A systematic review of the effectiveness of reducing health service interventions aimed at reducing inequalities in health. $\mathcal{F}$ Health Serv Res Policy 1996;1:93-103.

30 Reading R, Colver A, Openshaw S, et al. Do interventions that improve immunisation uptake also reduce social

31 Smith LK, Thompson JR, Woodruff G. Children's vision screening: impact on inequalities in central England. $\mathcal{F}$ Epidemiol Community Health 1995;49:606-9.

32 Audit Commission. Dear to our hearts. London: HMSO, 1995. 